\title{
Editorial
}

\section{CienCIA Y TRASCENDENCIA SE CONJUGAN PARA UNA MEJOR COMPRENSIÓN DEL HOMBRE}

La Universidad, partiendo de la realidad del contexto de vida, educa a los estudiantes y crea un clima favorable para el aprendizaje. Este clima está entretejido por los valores experimentados en la calidad de las relaciones interpersonales que unen a los docentes y estudiantes dentro de la comunidad universitaria.

En este itinerario educativo hay algunos elementos de calidad que una universidad ha de saber expresar: el respeto de la dignidad de cada persona y su unicidad; la riqueza de oportunidades ofrecidas a los jóvenes para crecer y desarrollar las propias capacidades y dotes; una equilibrada atención por los aspectos cognitivos, afectivos, sociales, profesionales, éticos, espirituales; el estímulo para que cada estudiante pueda desarrollar sus talentos en un clima de cooperación y solidaridad; la promoción de la investigación como compromiso riguroso frente a la verdad, con la conciencia de los límites del conocimiento humano, pero también con una gran apertura mental y de corazón; y el respeto de las ideas, la apertura a la confrontación, la capacidad de discutir y colaborar en un espíritu de libertad y atención por la persona.

En este sentido, la Universidad es el lugar en que se asumen los saberes y la dimensión de la investigación científica. Una de las principales responsabilidades de los docentes es acercar las estudiantes al conocimiento y a la comprensión de las conquistas del conocimiento y sus aplicaciones. Pero el compromiso por conocer e investigar no va separado del sentido ético y de lo trascendente. No hay verdadera ciencia que pueda descuidar sus consecuencias éticas y no hay verdadera ciencia que se aleje de la trascendencia. Ciencia y eticidad, ciencia y trascendencia no se excluyen recíprocamente, pero se conjugan para una mayor y mejor comprensión del hombre y de la realidad del mundo.

Ante los cambios vertiginosos de la sociedad, una propuesta de la educación integral exige una reflexión continua capaz de renovarla y de hacerla cada vez más rica en calidad. 
Se trata de una toma de posición clara: la educación que la escuela promueve no tiene por objetivo la meritocracia de una élite.

Aunque sea importante la búsqueda de la calidad y la excelencia, nunca hay que olvidar que los estudiantes tienen necesidades específicas. A menudo viven situaciones difíciles, y merecen una atención pedagógica que responda a sus exigencias. La universidad católica tiene que introducirse en el debate de las instancias mundiales sobre la educación inclusiva y aportar, en este ámbito, su experiencia y su visión educativa.

Se ha de garantizar la calidad de los propios sistemas académicos, localizando criterios e instrumentos de evaluación para valorizar la responsabilidad y la transparencia de cada carrera profesional e institución. Se trata de un objetivo plenamente acogido y compartido por todos, por el cual, en muchos casos se establecen acuerdos entre realidades especializadas, en el ámbito nacional e internacional, para localizar y compartir indicadores de medición que no se limiten a evaluar datos externos estadísticos y procedimientos sino que consideren también la finalidad y los contenidos de la educación superior, encuadrándolos en un horizonte de valores.

Promover la calidad de la educación universitaria significa evidenciar el valor de las actividades desarrolladas, consolidar sus aspectos positivos y mejorar aquellos carentes. Esta actividad de monitoreo y evaluación hoy es indispensable y desarrolla dos funciones fundamentales: ante todo una función pública, es decir hacer confiable y transparente el sistema de estudios, favoreciendo su conocimiento y una sana emulación entre distintas sedes de enseñanza; en segundo lugar, una función dirigida a alcanzar los objetivos institucionales y a reflexionar sobre el resultado de su actividad para mejorarla y desarrollarla.

Por otro lado, la transparencia de los resultados, la costumbre de dar cuentas a la sociedad, el empuje a la mejoría de los estándares alcanzados son aspectos que denotan la tendencia hacia el aumento de la calidad de la educación superior. Sin embargo conviene no perder de vista un aspecto fundamental de la educación, dado por el respeto de los tiempos de las personas y por la conciencia que los verdaderos cambios solicitan. La educación vive la metáfora del buen sembrador que se preocupa por sembrar, no siempre con la posibilidad de ver los resultados de su obrar.

Educar es actuar con esperanza y con confianza. La acción educativa y la enseñanza tienen que preocuparse por mejorarse continuamente y verificar la eficacia de los instrumentos, pero con la conciencia de no poder ver ni constatar todos los resultados deseados.

La voz de los estudiantes se expresa en el deseo de animar a ahondar en esta realidad tan rica y necesaria para la plenitud de la vida de cada ser humano y la relación entre todos. El desafío es intentar desentrañar su verdadero significado para poder reconocerla y vivirla hoy, en un momento en el que la superficialidad nos hace conformarnos con poco, con vínculos frágiles, que debilitan calidad de la verdadera compañía. Es tiempo de unir esfuerzos por una auténtica calidad universitaria.

Dr. Juan Roger Rodríguez Ruiz 